\title{
A Comparison of Radar Auroral Reflection Data With Acoustic Wave Theory ${ }^{1}$
}

\author{
Ray L. Leadabrand \\ Radio Physics Laboratory, Stanford Research Institute, Menlo Park, Calif.
}

(Received December 14, 1964)

\begin{abstract}
A comparison is made between 400 and $800 \mathrm{MHz}$ radar auroral reflection data and the concept that the irregularities in electron density responsible for the auroral echoes are plasma waves generated by instabilities in the ionospheric current system. The waves so generated would have their wave fronts parallel to the earth's magnetic field lines and would travel at the acoustic velocity of the medium. The comparison indicates that, although many of the key features of the plasma acoustic wave concept can be found in the radar auroral data, the spectral characteristics of the auroral echoes are much too complicated to be simply understood in their present form.
\end{abstract}

\section{Introduction}

Auroral radar echoes and radar echoes seen at lower latitudes from field-alined irregularities have long been shown to have many similar characteristics [Peterson, Villard, Leadabrand, and Gallagher, 1955; Dyce, Dolphin, Leadabrand, and Long, 1959]. It was not until 1960 that it seemed even remotely possible to explain field-alined radar echoes seen at the magnetic equator by the same mechanism used to explain auroral radar echoes. Bowles, Cohen, Ochs, and Balsley [1960] suggested that the irregularities are plane wave fronts whose wave fronts are parallel with the earth's magnetic field lines.

More recently, Buneman [1963] and Farley [1963a] have pointed out the possibility that the ionospheric current system as it exists in the ionosphere is similar to a "two-stream" instability system as described in modern plasma theory. They have suggested that the instabilities can generate plasma waves that are capable of giving rise to auroral reflections. These waves have wave fronts alined with the magnetic field lines of the earth and are expected to travel at the acoustic velocity of the medium. Bowles, Balsley, and Cohen [1963] and Cohen and Bowles [1963] have applied this concept to explain the existence of fieldalined $E$-region irregularities seen at the magnetic equator by Egan [1960] and others. Based upon this interpretation, they demonstrate that the experimental data appear to support the fact that the irregularities are most likely plane plasma acoustic waves that are generated by an instability resulting from the flow of current in the equatorial electrojet.

Measurements of the Doppler spectra from these irregularities indicate that the Doppler shift is independent of the elevation angle of the radar when looking either east or west magnetically, thus support-

1 The auroral radar data used in this paper were collected by SRI for the Rome Air Devel. opment Center under Contract AF $30(602)-1817$ and their support is gratefully acknowledged. ing the concept of plasma acoustic waves traveling transverse to the earth's magnetic field.

Bowles, Balsley, and Cohen [1963] have also shown that the scattered power at $50 \mathrm{MHz}$ and the $H$ magnetogram indicate that when the electrojet current increases to some value, the instability takes place, demonstrating the existence of a threshold effect in the reflection mechanism.

Based upon the suggestions of Bowles, Cohen, Ochs, and Balsley [1960], and more recently Buneman [1963], Farley [1963a and 1963b], Bowles, Balsley, and Cohen [1963], and Cohen and Bowles [1963] this theory of $E$-region field-alined equatorial irregularities may also be applicable to the auroral region.

An examination of existing radar auroral reflection data [Leadabrand, 1962] collected in Scotland at 400 and $800 \mathrm{MHz}$ was made in the light of the proposed mechanism.

\section{Description of Auroral Radar Data Col- lection Procedure}

From the fall of 1959 to the fall of 1960, the Stanford Research Institute operated a multifrequency auroral radar at Fraserburgh, Scotland, (57 $39^{\prime} 26^{\prime \prime}$ N latitude, $2^{\circ} 5^{\prime} 42^{\prime \prime} \mathrm{W}$ longitude). The principal parameters of the radar are shown in table 1 .

TABLE 1

\begin{tabular}{|c|c|c|}
\hline \multirow{2}{*}{ Parameter } & \multicolumn{2}{|c|}{ Frequency } \\
\hline & $400 \mathrm{MHz}$ & $800 \mathrm{MHz}$ \\
\hline $\begin{array}{l}\text { Transmitter peak power } \\
\text { Pulse length }{ }^{\text {a }} \text { (variable) } \\
\text { PRF a } \\
\text { Antenna beamwidth (142-ft diam } \\
\text { steerable parabola) }\end{array}$ & $\begin{array}{l}150 \mathrm{~kW} \\
50 \mu \mathrm{sec}, 300 \mu \mathrm{sec} \\
27 \text { or } 75 \mathrm{~Hz} \\
1.2 \mathrm{deg}\end{array}$ & $\begin{array}{l}50 \mathrm{~kW} \\
50 \mu \text { sec, } 300 \mu \text { sec } 2 \mathrm{~ms} \\
27 \text { or } 75 \mathrm{~Hz} \\
1.2 \mathrm{deg}\end{array}$ \\
\hline
\end{tabular}

a The values shown were used alternately at different times throughout the experiment. The majority of the Doppler data were collected at 2-ms pulse length and a PRF of $27 \mathrm{~Hz}$. 
The 142-ft diam parabolic antenna was rotated continuously in azimuth at the rate of one rotation each $3 \mathrm{~min}$. The antenna was stepped in elevation angle each rotation when pointing magnetic south. Five elevation angles $-0,2.5,4.5,8.5$, and $16 \mathrm{deg}$-were used to provide complete auroral region coverage. Thus once each $15 \mathrm{~min}$ a complete all-sky (the auroral region of interest) scan was made. Three such scans were made each hour. (The remaining $15 \mathrm{~min}$ of each hour were utilized for changing recording tape and other operational procedures.) The radar was operated for an 8-hr period each day. The beginning of the 8-hr period was changed each day by $8 \mathrm{hr}$ so that a 24-hr period was covered each four days.

The data were recorded on analog magnetic tape so that echo amplitude, Doppler spectra, and percent occurrence could be determined as a function of time and position in space. The existence of a magnetometer at Lerwick, Scotland, beneath the auroral reflection area made possible correlation of the radar data with magnetic activity.

\section{Presentation of Results}

In the paper of Bowles, Balsley, and Cohen [1963], two important characteristics of the equatorial field. alined reflection were used to demonstrate that the plasma acoustic wave mechanism appeared to be a valid explanation of the echoes. These two characteristics are reviewed here.

First, an examination of the spectral characteristics of the equatorial field-alined echoes indicated that essentially the same value of Doppler shift was obtained for differing antenna beam elevation angles, provided the antenna beam was oriented to look at right angles to the earth's magnetic field lines (that is, in a plane parallel to the circle formed by the magnetic equator). An example of the spectral data obtained by Bowles, Balsley, and Cohen [1963] is shown in figure 1. Examination of this illustration indicates that the Doppler shift (the peak in the spectra) occurs at essentially the same frequency for antenna beam elevation angles of $60 \mathrm{deg}$ west and $30 \mathrm{deg}$ west. It can also be seen in figure 1 that essentially the same Doppler shift (although of opposite sign) is obtained for antenna beam elevation angles of $30 \mathrm{deg}$ east and $30 \mathrm{deg}$ west. If the Doppler shifts are explainable in terms of simple irregularity drift, then the Doppler shift at antenna beam elevation angles of $30 \mathrm{deg}$ west and $60 \mathrm{deg}$ west should be quite different. These Doppler shift data, when interpreted in terms of velocity, give a value of about $360 \mathrm{~m} / \mathrm{s}$. Thus the interpretation assigned to the Doppler shift data is that the reflections are arising from plasma waves whose wave fronts are alined with the magnetic field lines and are traveling at the acoustic velocity $(360 \mathrm{~m} / \mathrm{s}-$ a reasonable estimate for the acoustic velocity at $E$-region height). The asymmetry between $30 \mathrm{deg}$ west and $30 \mathrm{deg}$ east is explained in terms of the direction of flow of the electrons forming the equatorial electrojet current system; the twostream instability theory would indicate that the direction of travel of plasma waves generated by this process would, in general, be in the direction of the velocity vector of the stream.

Thus, it would appear that if this mechanism is also responsible for the generation of auroral irregularities, then a detailed examination of the auroral Doppler spectra should yield similar results.

The auroral geometry with regard to the position in space that the radar looks at right angles to the earth's
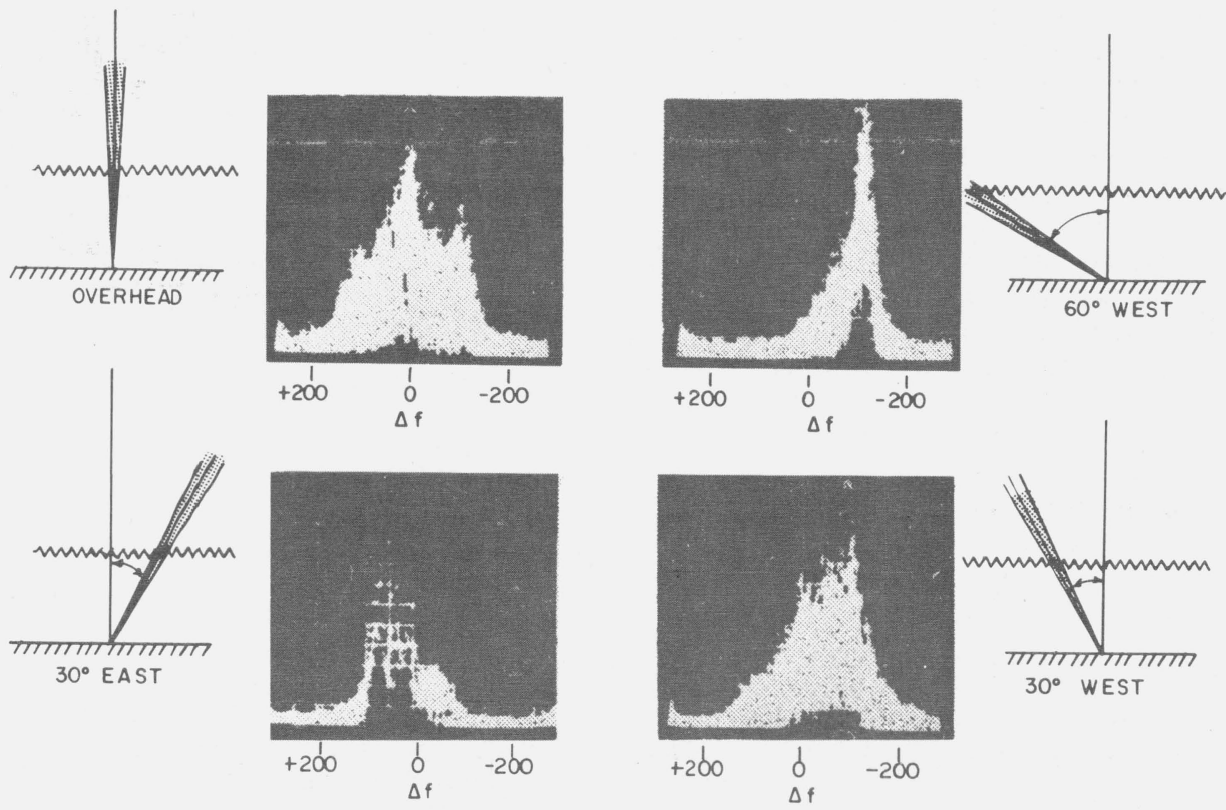

FiguRE 1. Spectra of equatorial echoes related to the direction of the propagating path. Source: Bowles et al. [1963]. 
magnetic field line is much more complicated than the equivalent geometry for the magnetic equator. Remembering that the Scotland radar antenna was rotated constantly in azimuth angles at particular elevation angles, the radar line of sight looks at right angles to the earth's magnetic field lines twice each azimuth scan for any particular range interval. This relationship can be seen in figure 2 , where the offperpendicular angle and amplitude are plotted against azimuth angle. It can be seen that the amplitude at the auroral echoes peaks at azimuth angles corresponding to zero-degree off-perpendicular angles. For a different range interval the azimuth angle (and hence, height) where the radar line-of-sight intersects the magnetic field lines at right angles is different. Thus, as the radar antenna rotates in azimuth, it continues to look at right angles to the earth's magnetic field, but for differing ranges and heights. For this complicated auroral geometry, a comparison of what the auroral spectra should resemble, based upon simple geometrical considerations, for the irregularity drift model and for the plasma acoustic wave model is shown in figure 3 . In figure $3 \mathrm{~b}$ it can be seen that the Doppler shift (the peak of the spectra) does not move with azimuth angle for the plasma acoustic wave model. In addition, for the magnetic north direction, the spectra become double peaked and at nonmagnetic north directions the spectrum is nonsymmetrical about the peak Doppler shift. In comparison with figure $3 \mathrm{a}$ it can be seen that the Doppler shift moves with azimuth angle for the irregularity drift model. In the irregularity drift model it can be seen that the spectra is symmetrical at an azimuth corresponding to magnetic north.

In order to determine which model the Scotland auroral Doppler shift data fits, a plot of the Doppler shift (peak of the auroral spectra) versus azimuth angle is shown in figure 4. Although the plot shows considerable scatter, it can be seen that the Doppler shift does not remain perfectly constant as a function of azimuth angle although there is a weak trend in that direction. The mean of the maximum Doppler shift at azimuths away from magnetic north is shown in figure 4 to be about $1.5 \mathrm{kHz}$ although the spread in the spectral shift varies from 1 to $2 \mathrm{kHz}$. As the velocity corresponding to the Doppler shift is given by

$$
\text { Velocity }=\frac{\text { Doppler shift } \times \text { wavelength }}{2}
$$

the velocities corresponding to the range of Doppler shift values are 375 to $750 \mathrm{~m} / \mathrm{s}$. In order to examine the auroral spectra in more detail, typical $400-\mathrm{MHz}$ auroral apectral data as a function of azimuth angle are shown in figure 5 .

Comparison of the details of the spectral shapes and locations shown in figure 5 with spectra based upon a plasma acoustic wave mode shown in figure $3 \mathrm{a}$ indicates a number of similarities. First, several of the spectra shown for particular azimuth angles have nonsymmetrical shapes, as would be expected in the plasma acoustic wave model. In addition, the spectra shown in figure 5 for $340 \mathrm{deg}$ azimuth (nearly magnetic north) has a tendency for the double-humped spectra that would be expected from the plasma acoustic model for the magnetic north direction. However, a plot of the Doppler shift (peak of the spectra) versus azimuth angle, based upon the spectra shown in figure 5 , would not be constant as would be expected from the plasma acoustic model.

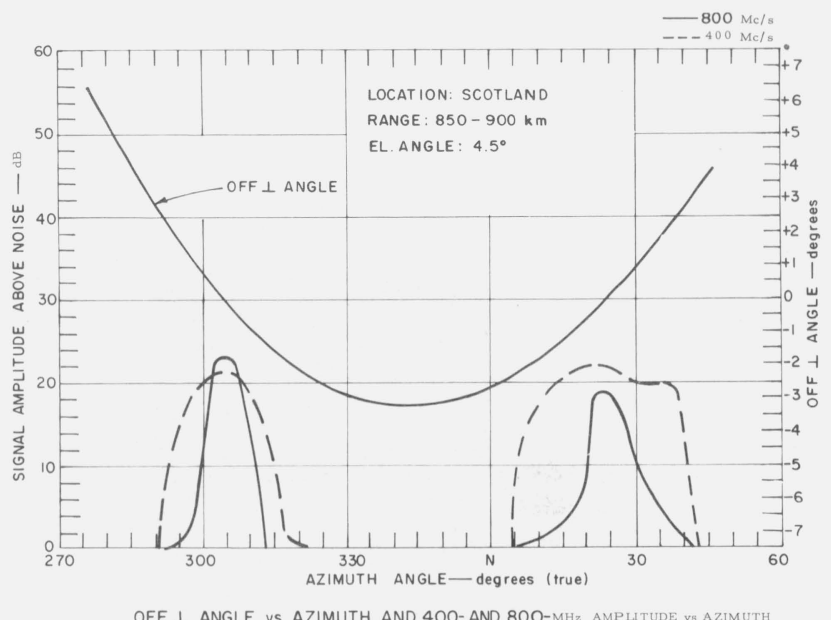

Figure 2. Off-perpendicular angle versus azimuth and 400-MHz and $800-\mathrm{MHz}$ auroral echo amplitude versus azimuth.

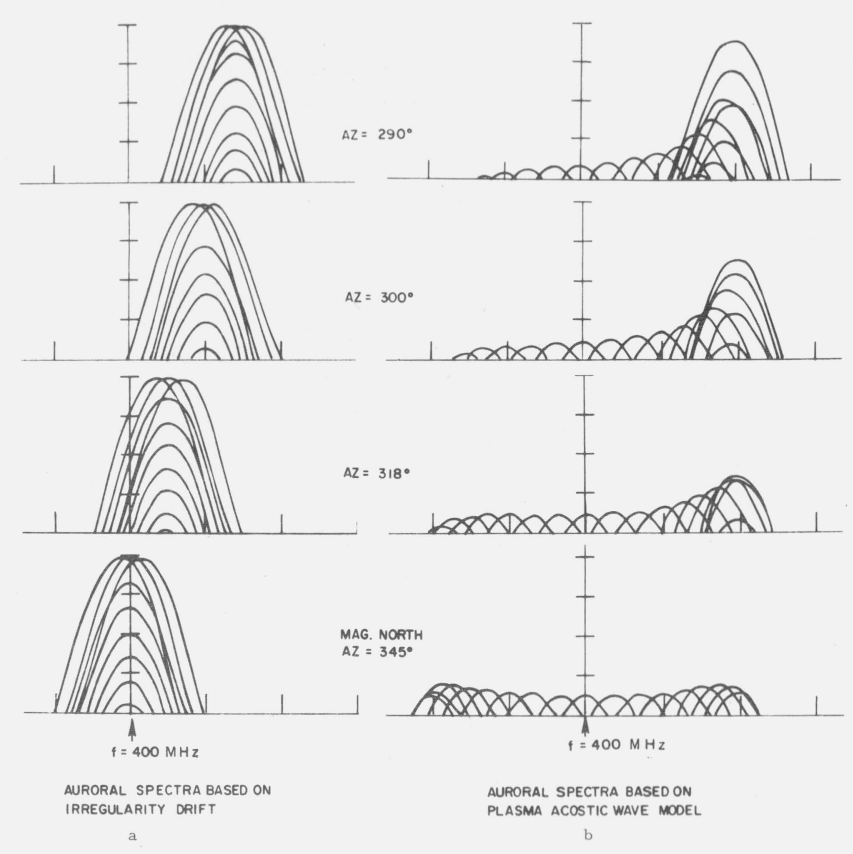

FigURE 3. Sketch shows auroral echo spectra based upon simple geometrical considerations for plasma acoustic wave and irregularity drift models. 


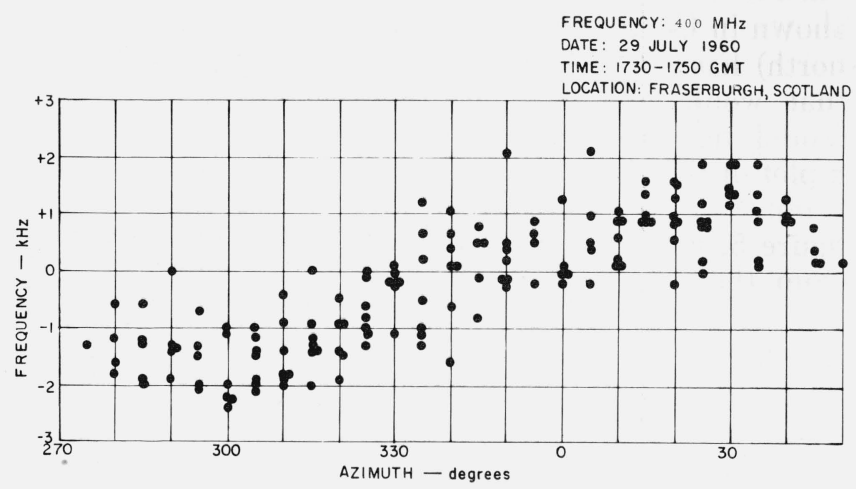

RECEIVED DOPPLER FREQUENCY VS ANTENNA AZ!MUTH ANGLE

FIGURE 4. Auroral echo Doppler shift versus antenna azimuth angle.

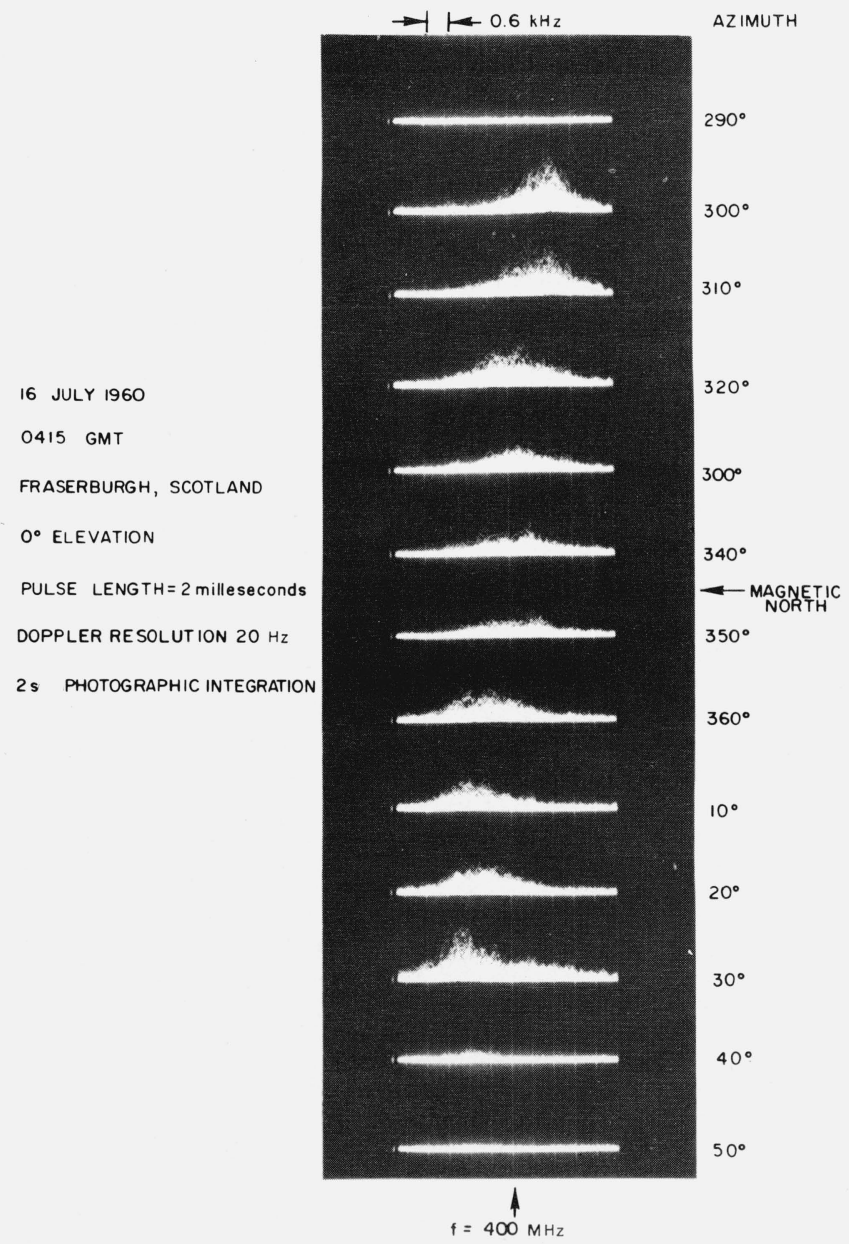

FigURE 5. Auroral echo Doppler spectra versus antenna azimuth angle.

The second characteristic of the equatorial fieldalined reflections used by Bowles, Balsley, and Cohen [1963] to demonstrate that the plasma acoustic mechanism appeared valid was the threshold effect. They found that no $E$-region field-alined irregularities were seen until the horizontal magnetic field strength (and hence, the intensity of the electrojet) increased above some particular level and from then on the magnetic field strength and echo strength appear to be roughly proportional. This effect as shown by Bowles, Balsley, and Cohen [1963] (see fig. 6 of the present paper) also shows a hysteresis effect. That is, the value of magnetic field strength adequate to keep the mechanism operating is smaller than that needed to start the effect.

These results have been interpreted to indicate that the intensity of the electrojet must reach some value before it becomes unstable and generates the plasma acoustic waves. The intensity of the electrojet required to continue generating the instabilities appears to be less than that required to start them.

The auroral radar data from Scotland were examined to determine the existence of such a threshold effect. First, the magnetometer at Lerwick (beneath the auroral reflecting region) allowed a comparison of auroral echo amplitude and magnetic activity similar to that made by Bowles, Balsley, and Cohen [1963]. A number of such comparisons were made; two typical examples are shown in figure 7 . The first example in figure 7a shows the $H$ component of magnetic activity increased until auroral echoes suddenly start to occur. After that, the relationship between magnetic activity and echo amplitude becomes very complicated (although roughly proportional) and it is difficult to see a pronounced hysteresis effect, although the last five data points appear to give such a trend. The complicated relationship between echo amplitude and magnetic activity is not particularly surprising, as the very nature of the aurora is so much more complicated than the comparatively simple nature of the equatorial ionosphere. The second example, shown in figure $7 \mathrm{~b}$ is much simpler, showing clearly the threshold effect. Again, however the relationship between magnetic activity and echo strength does not indicate the existence of a hysteresis effect although the echo amplitude and magnetic activity are roughly proportional.

The echo amplitude distribution versus number of occurrences was examined for a threshold effect in the following way. As pointed out earlier, the radar line of sight intersects the magnetic field lines at right angles twice each azimuth scan. The data shown in figure 2 clearly demonstrate this; also, the echo amplitude is seen to peak sharply when this orthogonality condition is met. A plot of the amplitude of these peaks was made versus the number of such peaks and the relationship shown in figure 8 was obtained. It can be seen that the data yielded no amplitude values that were less than a signal-to-noise ratio of approximately $15 \mathrm{~dB}$. Even though the radar is capable of seeing weaker echoes, none were found to exist when only those echoes resulting from looking at right angles to the earth's magnetic field lines were used as data points. Thus, whatever mechanism responsible for the creation of the auroral ionized irregularities is capable of producing these only at an intensity above some threshold value. Previous auroral radar ampli- 
tude distributions did not show such a threshold effect [Presnell, Leadabrand, Peterson, Dyce, Schlobohm, and Berg, 1959], probably due to the fact that the previous studies used radars about $30 \mathrm{~dB}$ less sensitive than the Scotland radar.

As part of earlier studies of the Scotland auroral echo data, Leadabrand [1962] presented experimental curves of the aspect sensitivity of auroral echoes at 400 and $800 \mathrm{MHz}$. These curves of amplitude versus off-perpendicular angles are shown in figure 9 and are compared with the theoretical expectations of aspect sensitivity that would result from the Booker scattering equation [Booker, 1956]. It can be seen that not only do the experimental curves have the wrong shape as compared to the Booker theory, but they also indicate that the aspect sensitivity is weakly dependent upon the radar frequency. It is possible that the lack of dependence of aspect sensitivity on radar frequency is another indication that the radar auroral echoes are arising from plane waves alined with the earth's magnetic field rather than ellipsoidal blobs alined with the earth's magnetic field. That is, it would appear that the radar selects the family of plane waves whose wave front spacing would enhance the echo amplitude, rather than reflecting from field-alined blobs of finite length.

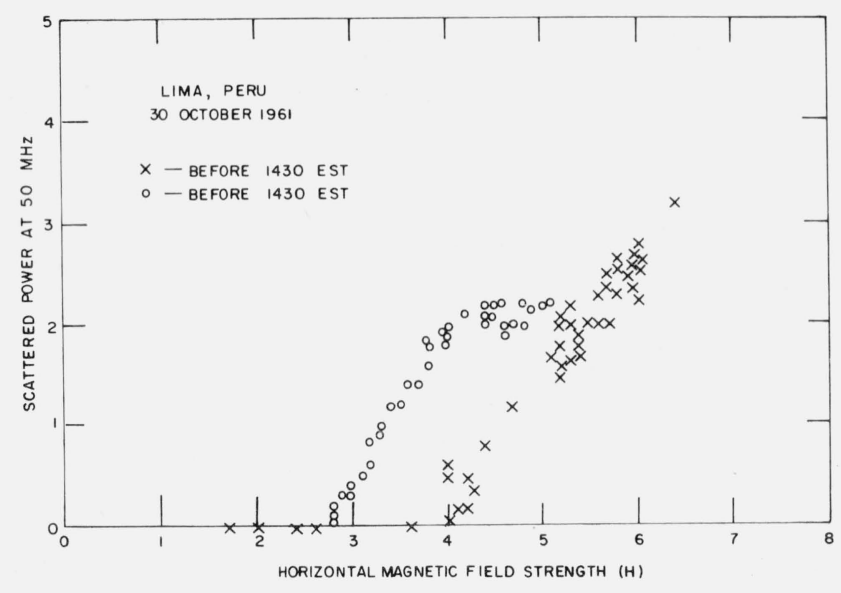

FIGURE 6. The relationship between the scattered power at $50 \mathrm{MHz}$ and the $\mathrm{H}$ magnetogram trace. Source: Bowles et al. [1963].
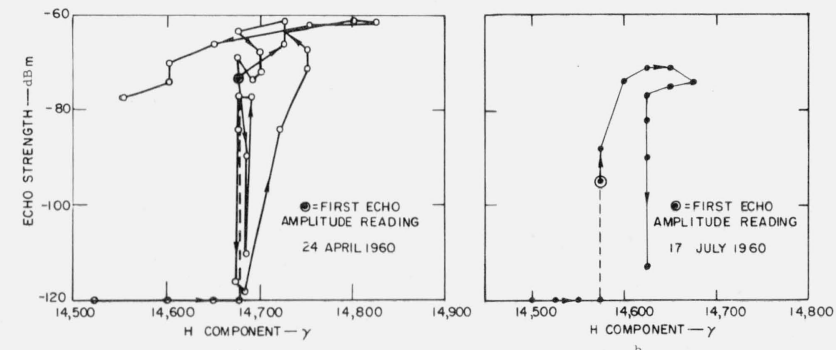

FIGURE 7. The relationship between 400-MHz auroral echo power at $400 \mathrm{MHz}$ and the $\mathrm{H}$ component of magnetic field strength.

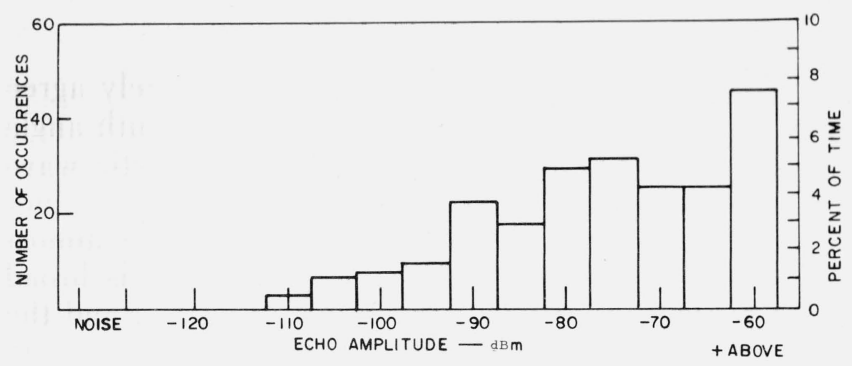

FIGURE 8. Maximum 400-MHz auroral echo strength versus number of occurrences.

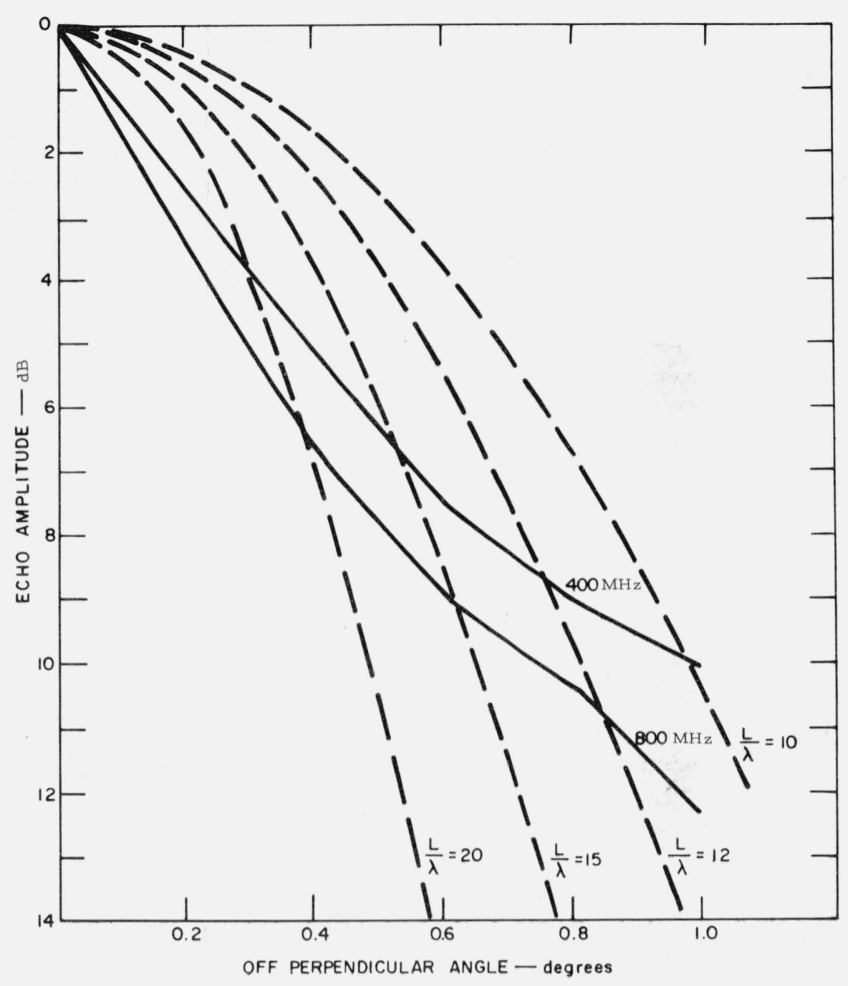

FIGURE 9. Aspect sensitivity showing experimental echo amplitude versus off-perpendicular angle compared with theory.

\section{Discussion of Results}

In the previous section it has been shown that the radar auroral reflection data do have many of the necessary characteristics that are unique to the plasma acoustic wave model for the generation of such irregularities as proposed by Bowles, Balsley, and Cohen [1963]. That is, the auroral radar data indicate the existence of a threshold effect as do the equatorial field-alined echoes and the auroral spectral data have many of the unique features found in the equatorial field-alined echo spectra. Although the auroral data exhibit many of the desired characteristics, the agreement is not perfect in a number of ways. 
First, the auroral spectra do not completely agree with the constant Doppler shift versus azimuth angle that would be expected for the plasma acoustic wave model. Although the scatter plot (fig. 4) of Doppler shift versus azimuth angle appears to exhibit almost the proper trends, the scatter of the points is broad enough that both the irregularity drift model and the plasma acoustic wave model appear to fit the data equally well. The examination of the detailed spectra is much more encouraging. Even though the Scotland auroral radar antenna was not scanned so that the echoes arose from a constant magnetic latitude line, the spectra obtained appear to exhibit many of the desired detailed characteristics.

It is important to note, however, the relatively high velocity represented by the Doppler shifts shown in both figures 4 and 5 . In figure 4 the range of velocities is 375 to $750 \mathrm{~m} / \mathrm{s}$ and in figure 5 the $1.2 \mathrm{kHz}$ Doppler shift is equivalent to a velocity of $450 \mathrm{~m} / \mathrm{s}$. This is of course a somewhat higher velocity for the value of acoustic velocity in the $E$ region than the $360 \mathrm{~m} / \mathrm{s}$ found by Bowles, Balsley, and Cohen [1963], but when one considers the higher temperatures that are usually found in the aurora [Dalgarno, 1964] than would exist at the magnetic equator, the velocities from the auroral spectra are considered reasonable for the acoustic velocity.

The lack of hysteresis in the relationship between auroral echo amplitude and magnetic field strength is not considered unreasonable in light of the complexity of the auroral ionosphere. The definite threshold effect exhibited in both the amplitude versus occurrence data and in the amplitude versus magnetic activity is considered to be remarkably similar to the data shown for the equatorial region by Bowles, Balsley, and Cohen [1963].

\section{Conclusions}

The theory for the generation of plasma acoustic waves proposed as an explanation for equatorial fieldalined echoes appears to also fit much of the radar auroral data that are presently available. Considering the fact that the auroral data were not originally collected with this theory in mind, it is believed that the fit is extremely good. The relatively minor differences in the auroral data and the equatorial data as far as the plasma acoustic wave model is concerned appear easily reconciled when the general degree of complexity of the aurora is considered and the fact that the auroral data were not collected in the way most likely to make the comparison easy.
It appears that this model is, at the present time, the most likely explanation of auroral irregularities that has been proposed for some time. It is expected that efforts to establish the validity of this model as an explanation for auroral reflections should yield interesting and valuable results.

It is planned to conduct further auroral radar experiments in the near future to obtain data in a form more suitable for such comparisons.

\section{References}

Booker, H. G. (1956), A Theory of scattering of non-isotropic irregularities with applications to radar reflection from the Aurora, J. Atmospheric Terrst. Phys. 8, Nos. 4/5, p. 204.

Bowles, K. L., B. B. Balsley, and R. Cohen (1963) Field-aligned E-region irregularities identified with acoustic plasma waves, J. Geophys. Res. 68, No. 9, 2485.

Bowles, K. L., R. Cohen, G. R. Ochs, and B. B. Balsley (1960), Radio echoes from field-aligned ionization above the magnetic equator and their resemblance to Auroral echoes, J. Geophys. Res. 65, No. 6, 1853.

Buneman, O. (1963), Excitation of field-aligned sound waves by electron streams, Phys. Rev. Letters 10, No. 7, 285.

Cohen, R., and K. L. Bowles (1963), The association of plane-wave electron-density irregularities with the equatorial electrojet, J. Geophys. Res. 68, No. 9, p. 2503.

Dalgarno, A. (1964), Interaction of energetic particles with the atmosphere, presented at Symposium on Auroras, Lockheed Missiles and Space Company, 16 January, Palo Alto, Calif.

Dyce, R. B., L. T. Dolphin, R. L. Leadabrand, and R. A. Long (1959), Aurora-like echoes observed from $17^{\circ}$ latitude, J. Geophys. Res. 64, No. 11, 1815.

Egan, R. D. (1960), Anisotropic field-aligned ionization irregularities in the ionosphere near the magnetic equator, J. Geophys. Res. 65, No. 8, 2343.

Farley, D. T., Jr. (1963a), The two-stream instability as a source of irregularities in the ionosphere, Phys. Rev. Letters 10, No. 7, 279.

Farley, D. T., Jr. (1963b), A plasma instability resulting in fieldaligned irregularities in the ionosphere, J. Geophys. Res. 68, No. 22, 6083.

Leadabrand, R. L. (1962), Radio studies of the Aurora, J. Phys. Soc. Japan 17, Supp. A-1.

Peterson, A. M., O. G. Villard, R. L. Leadabrand, and P. B. Gallagher (1955), Regularly-observable aspect-sensitive radio reflections from ionization aligned with the earth's magnetic field and located within the ionospheric layers at middle latitudes, J. Geophys. Res. 60, 497-512.

Presnell, R. I., R. L. Leadabrand, A. M. Peterson, R. B. Dyce, J. C. Schlobohm, and M. R. Berg (1959), VHF and UHF radar observations of the Aurora at College, Alaska, J. Geophys. Res. 64, No. 9, 1179. 